\title{
Oportunidades de Melhorias: Qualidade do Serviço Prestado em Escolas Públicas
}

\section{Improvement Opportunities: Quality Service in Public Schools}

\author{
Evadio Pereira Filho * \\ Fernando Antônio Guimarães Tenório \\ Junior Raimundo da Silva \\ Instituto Federal de Educação, Ciência e Tecnologia da Paraíba
}

\begin{abstract}
O artigo avalia a qualidade do serviço ofertado por escolas públicas situadas no sertão paraibano e adjacências. Para isto, foram apreendidos as expectativas (importância) e o desempenho em relação a um conjunto de 18 atributos; os quais estão relacionados aos docentes (conhecimento técnico, didática, estímulo ofertado aos alunos), aos aspectos tangíveis (salas de aula, banheiros, biblioteca), aos materiais didáticos disponíveis, à organização escolar (horários, serviços administrativos) e à reputação institucional. Foi utilizado um questionário estruturado para capturar as respostas de 1394 alunos de dezessete instituições de ensino. Com o auxílio do Statistical Package for the Social Science - SPSS, versão 19.0, foram extraídas estatísticas descritivas e realizado o teste de Spearman. Os resultados relevaram que o padrão de expectativas dos alunos, em essência, foi heterogêneo. Em geral, os atributos mais valorizados referem-se aos docentes (conhecimento e estímulo), ao passo que aqueles relacionados à infraestrutura (internet, recursos multimídias e segurança) foram percebidos como menos importantes. Ademais, o conjunto de ações apontado pelas matrizes de posicionamento competitivo e de avaliação de desempenho podem subsidiar às decisões gerenciais de aperfeiçoamento dos níveis de serviço prestados pelas escolas públicas.
\end{abstract}

Palavras-chave: Qualidade do serviço, Instituiç̃es públicas de ensino, Sertão paraibano, Expectativas, Desempenho.

The article evaluates the quality of the service offered by public schools located in Paraiba and adjacencys. For this, were captured expectations (importance) and performance in relation to a set of eighteen attributes; which are related to teachers (technical knowledge, didactics, incentives offered to students), the tangible aspects (classrooms, toilets, library), the teaching materials available, school organization (timetables, administrative services) and institutional reputation. We used a structured questionnaire to capture the 1394 students answers from seventeen educational institutions. With the support of Statistical Package for Social Science SPSS, version 19.0, descriptive statistics were extracted and the Spearman test was performed. The results showed that the standard of students' expectations, in essence, is heterogeneous. In general, the most valued attributes refer to teachers (knowledge and stimulus), while those related infrastructure (internet, multimedia resources and safety) were perceived as less important. Moreover, the set of actions appointed by competitive positioning matrix and performance evaluation matrix can assist in management decisions to improve the service levels provided by public schools.

Keywords: Quality service, Public schools, Paraiba backlands, Expectations, Performance.

*Contacto: evadio.filho@gmail.com

ISSN: $1696-4713$

www.rinace.net/reice/

revistas.uam.es/reice
Recibido: $\quad 16$ de julio 2016

$1^{\text {a }}$ Evaluación: 30 de septiembre 2016

$2^{\text {a }}$ Evaluación: 1 de noviembre 2016

Aceptado: 2 de diciembre 2016 


\section{Introdução}

A indústria de serviços exerce papel de relevo no cenário econômico mundial (Cronin e Taylor, 1992). No Brasil, entre 2003 e 2013, houve um crescimento de 33,9\% no quantitativo de empresas que possuíam o serviço como atividade principal. Esse segmento abrangia cerca de 1,2 milhão de firmas, as quais contribuíram para quadruplicar a receita líquida ( $\mathrm{R}$ 1,3 milhão) e duplicar o índice de empregos formais 12, 5milhões (IBGE, 2013). Nessa seara, situa-se a educação como um dos serviços ofertados à sociedade, e a qual deverá ser executada pelo Estado sob a regência de princípios tal como a garantia de padrões mínimos de qualidade.

O mercado do ensino vem ampliando a sua oferta (Butta e Rehman, 2010). O contingente de escolas brasileiras de ensino médio, no período de 2008 a 2014, saltou de 25.389 para 27.743 estabelecimentos. Dentre estes, mais de 19 mil são públicos. No tocante ao número de matrículas, em 2014, foram efetivadas, no ensino médio, aproximadamente 8,3 milhões; sendo 86,7\% executadas em instituições públicas de ensino (INEP, 2015).

As estatísticas apontam que o segmento da educação possui uma concorrência intensa e equânime à de qualquer outra indústria (Souza et al., 2014). Entretanto, à proporção que se estende a oferta, os alunos tornam-se mais exigentes em relação aos serviços recebidos, pois são vistos como os efetivos beneficiários do ato (Lovelock e Wrigth, 2006). Como corolário, a falha na prestação do serviço poderá conduzir a um estado de insatisfação dos discentes, podendo levá-los a promover a troca de instituição de ensino (turnover) ou até ao abandono da vida acadêmica.

Por conseguinte, as organizações, para sobreviverem em uma arena hipercompetitiva, necessitam investir cada vez mais em qualidade de serviço como uma estratégia de diferenciação (Fitzsimmons e Fitzsimmons, 2005; Ramos, 2015). Nesse diapasão, Ramseook-Munhurrun e Nundlall (2013) e Ashraf, Osman e Ratan (2016) asseveraram que a procura de excelência no ambiente educativo está em ascensão, figurando como uma das principais preocupações dos gestores da área.

À luz do exposto, o presente trabalho tem como objetivo analisar a qualidade do serviço ofertado por dezessete escolas públicas situadas no sertão paraibano e adjacências. Para tanto, foram apreendidas as expectativas (importância) de 1394 alunos e suas percepções de desempenho em relação a um conjunto de 18 atributos.

\section{Fundamentação teórica}

$\mathrm{Na}$ indústria do serviço, a qualidade proporciona o alcance de vantagem competitiva (Ali et al., 2016; Dos Santos, 2014; Eberle, 2009; Fitzsimmons e Fitzsimmons, 2005; Ramos, 2015;). Segundo Grönroos (1984), a conformidade entre aquilo que o cliente espera receber (expectativas) e o que efetivamente foi recebido (percepção de desempenho) simboliza a qualidade do serviço. Quando uma empresa possui desempenho igual ou superior às expectativas do cliente; houve qualidade na prestação do serviço a qual despertará uma satisfação no consumidor. Caso contrário, reinará um estado de insatisfação na clientela. Portanto, os gestores necessitam compreender as discrepâncias entre os serviços esperado e recebido. Isso evitará decisões equivocadas, ineficiência 
operacional (emprego inadequado dos recursos) e a consequente ruptura da fidelidade dos clientes (Grönroos, 1984).

Tumino e Poitevin (2013) relatam que a qualidade do serviço é um fenômeno multidimensional, e, consoante Grönroos (1984), sua avaliação ocorre, basicamente, por duas dimensões: a técnica e a funcional. A primeira representa a qualidade dos resultados desejados pelos clientes. Refere-se àquilo que os consumidores recebem da empresa. Por sua vez, a outra, aponta para a maneira como as interações transcorrem entre prestador de serviço e cliente. Em uma universidade, por exemplo, a dimensão técnica compreende os conteúdos, as pesquisas e as atividades de extensões. Já a dimensão funcional advém do relacionamento com o corpo docente e administrativo, assim como da infraestrutura (prédios, laboratórios e equipamentos) ofertados aos alunos (Eberle, Milan e Lazzari, 2010).

Para Ali e colaboradores (2016), a qualidade em educação não se restringe tão somente aos padrões educacionais, habitualmente, idealizados e julgados pelos alunos. Os autores reforçam que a concepção dessa terminologia engloba às mudanças significativas no próprio sistema educacional, na natureza das suas entradas, nos currículos, nas tecnologias educacionais, no ambiente socioeconômico, cultural e político em qual está inserido. Asseguram que a maioria dos educadores também incluem, na definição, a natureza das experiências educacionais que ajudam a produzir os resultados: o ambiente de aprendizagem (Ali et al., 2016)

Todavia, os aspectos da intagibilidade e heterogeneidade, os quais cercam a concepção de serviço, alimentam a insegurança do consumidor (Parasuraman, Zeithaml e Berry, 1985). Por isso, a avaliação da qualidade do serviço perpassa pela delimitação de atributos operacionalizáveis que melhor representem o contexto pesquisado.

Ademais, a qualidade dos serviços educacionais é um campo fértil e afluente, em que diversos estudos apontam nessa direção (Ali et al., 2016; Ashraf, Osman e Ratan, 2016; Dos Santos, 2014; Milan, Corso e Eberle, 2013; Ramseook-Munhurrun e Nundlall, 2013).

\subsection{Estudos empíricos sobre gestão da qualidade em instituições de ensino}

A educação carece da adoção de ferramentas capazes de monitorar a qualidade e a satisfação dos clientes (Ali et al., 2016; Ramseook-Munhurrun e Nundlall, 2013). Há uma miríade de estudos que visam contribuir com essa lacuna acadêmica e que enumeram atributos dos serviços educacionais.

Alguns literários (Alcântara et al., 2012; Deshields, Kara e Kaynak, 2005; Navarro, Iglesias e Torres, 2005; Butta e Rehman, 2010;) avaliaram o nível de satisfação de universitários com suas respectivas instituições de ensino. Constataram que know-how e atitude dos docentes, métodos de ensino aplicados e a coordenação do curso representam os elementos que mais atuam sobre a satisfação do aluno e que merecem maior atenção gerencial. Já outros teóricos (Annamdevula e Shekhar, 2012; Eberle, 2009; Mostafa, 2007) investigaram sobre a robustez das cinco dimensões de qualidade propostas pelo SERVQUAL: tangibilidade (referente aos aspectos físicos), confiabilidade (cumprir o que foi prometido com exatidão), responsividade (capacidade de ajudar os usuários), garantia (segurança fornecida através das operações) e empatia (atenção individualizada ao usuário). Em geral, esse conjunto genérico de dimensões não foi sustentado pois uma 
diversidade maior foi identificada nos estudos, indicando tão somente que a qualidade é um construto multidimensional.

A tabela 1 ilustra os vinte e quatro trabalhos empíricos que serviram como fontes para identificar os atributos que melhor descrevem os serviços acadêmicos.

Tabela 1. Inventário dos estudos empíricos que contêm atributos do serviço educacional

\begin{tabular}{|c|c|c|c|}
\hline AUTOR/ANo & PAÍS & AUTOR/ANO & PAÍS \\
\hline $\begin{array}{l}\text { Deshields., Kara e Kaynak } \\
(2005)\end{array}$ & EUA & Annamdevula e Shekhar (2012) & Índia \\
\hline $\begin{array}{l}\text { Navarro, Iglesias e Torres } \\
(2005)\end{array}$ & Espanha & Cardona e Bravo (2012) & Colômbia \\
\hline $\begin{array}{l}\text { Lorenço e colaboradores } \\
(2006)\end{array}$ & Brasil & Nyagowaa, Ocholla e Mutula (2013) & Quênia \\
\hline Abdullah (2006) & Malásia & Milan, Corso e Eberle (2013) & Brasil \\
\hline Mostafa (2007) & Egito & $\begin{array}{l}\text { Ramseook-Munhurrun e Nundlall } \\
(2013)\end{array}$ & Maurícias \\
\hline Eberle (2009) & Brasil & Dos Santos (2014) & Brasil \\
\hline Brochado (2009) & Portugal & Souza e colaboradores (2014) & Brasil \\
\hline Butta e Rehman (2010) & Paquistão & Duarte e Piratelli (2015) & Brasil \\
\hline $\begin{array}{l}\text { Cunha, Andrade e Brandão } \\
(2010)\end{array}$ & Brasil & Lankara e Ye (2015) & Mianmar \\
\hline Vergara e Quesada (2011) & Colômbia & Ramos (2015) & Brasil \\
\hline $\begin{array}{l}\text { Campos, Martins e Neto } \\
(2011)\end{array}$ & Brasil & Ali e colaboradores (2016) & Malásia \\
\hline $\begin{array}{l}\text { Alcântara e colaboradores } \\
(2012)\end{array}$ & Brasil & Ashraf, Osman e Ratan (2016) & Bangladesh \\
\hline
\end{tabular}

Fonte: Elaborada pelos autores.

A escolha dos autores por esses estudos pauta-se nos seguintes critérios: contemporaneidade e adequação dos trabalhos ao recorte temático pesquisado, presença de variáveis que retratassem os serviços educacionais.

\subsection{Matrizes de posicionamento competitivo e de avaliação de desempenho}

Stock e Lambert (2001) propuseram dois frameworks que devem ser utilizados conjuntamente para orientar a formulação de estratégias que permitam construir e sustentar diferencial competitivo. O primeiro é a matriz de posicionamento competitivo (figura 1) que traça um diagnóstico sobre quais elementos da organização agregam maior valor aos consumidores, proporcionando vantagem frente à concorrência.

A ferramenta relaciona o desempenho da empresa perante os demais players (desempenho relativo) e a importância conferida pelos clientes ao atributo (Stock e Lambert, 2001). Para fins de apreensão do desempenho relativo, calcula-se as lacunas entre as avaliações de desempenho de uma firma e do seu principal concorrente (benchmark). Do cruzamento, surgem nove células, dentre as quais, destacam-se aquelas rotuladas "maior força" e "maior fraqueza".

Caso os atributos situem-se no campo "maior força", a empresa deverá implementar ações de marketing que os enfatizem, pois são itens altamente valorizados pelos clientes e onde o desempenho organizacional supera as práticas dos rivais. Por sua vez, os elementos posicionados na célula "maior fraqueza" necessitam ser aperfeiçoados com urgência. Englobam atributos de alta importância, porém há, no setor, outras firmas que 
os executam de forma mais eficiente e eficaz do que a organização analisada (Stock e Lambert, 2001).

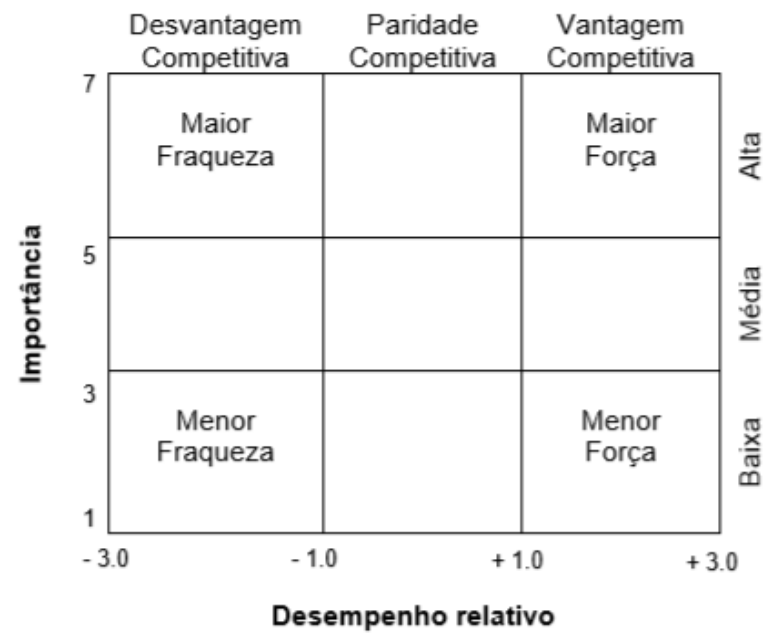

Figura 1. Matriz de posicionamento competitivo Fonte: Stock e Lambert (2001).

O outro construto trata-se da matriz de avaliação de desempenho (figura 2), do tipo quadrada de ordem 3, composta por nove células a partir da interseção entre as seguintes variáveis: importância de cada atributo e o desempenho da empresa neles. Cada célula sugere ações, no entanto, distingue-se da anterior por não contemplar os demais competidores. O objetivo desta ferramenta é identificar áreas que oferecem a máxima oportunidade de melhoria.

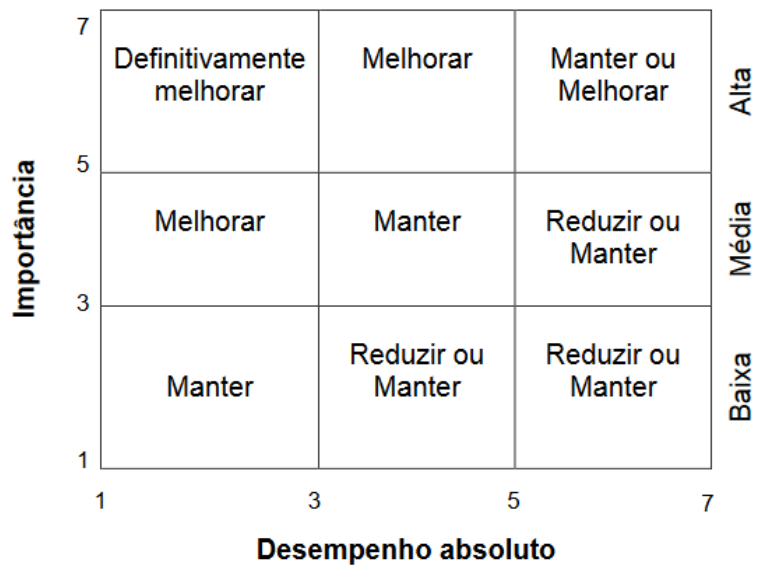

Figura 2. Matriz de avaliação de desempenho Fonte: Stock e Lambert (2001).

Por exemplo, para aqueles atributos de alta importância e em que o desempenho da firma é muito baixo, os gestores devem implementar ações corretivas de forma prioritária e imediata pois negócios provavelmente estão sendo desperdiçados em decorrência desse déficit de qualidade. Já os atributos de baixa importância e em que a organização apresenta um desempenho elevado são vistos como zonas de excesso. Portanto, sugere- 
se desinvestir rapidamente e realocar os recursos em itens que recaiam nos fragmentos "definitivamente melhorar" ou "melhorar".

\section{Metodologia}

O esquema metodológico, ilustrado na figura 3, foi adotado nesse estudo. De início, foi desenvolvida uma revisão de literatura, nacional e internacional, sobre a teoria da qualidade em serviços e os estudos empíricos em ambientes de ensino que abordavam essa temática. Nessa etapa, os propósitos foram construir o arcabouço teórico, catalogar os atributos que descrevem os serviços educacionais e selecionar, dentre os instrumentos de pesquisa já validados, aquele que mensure a qualidade dos serviços educacionais, de forma mais apropriada ao cenário da pesquisa.

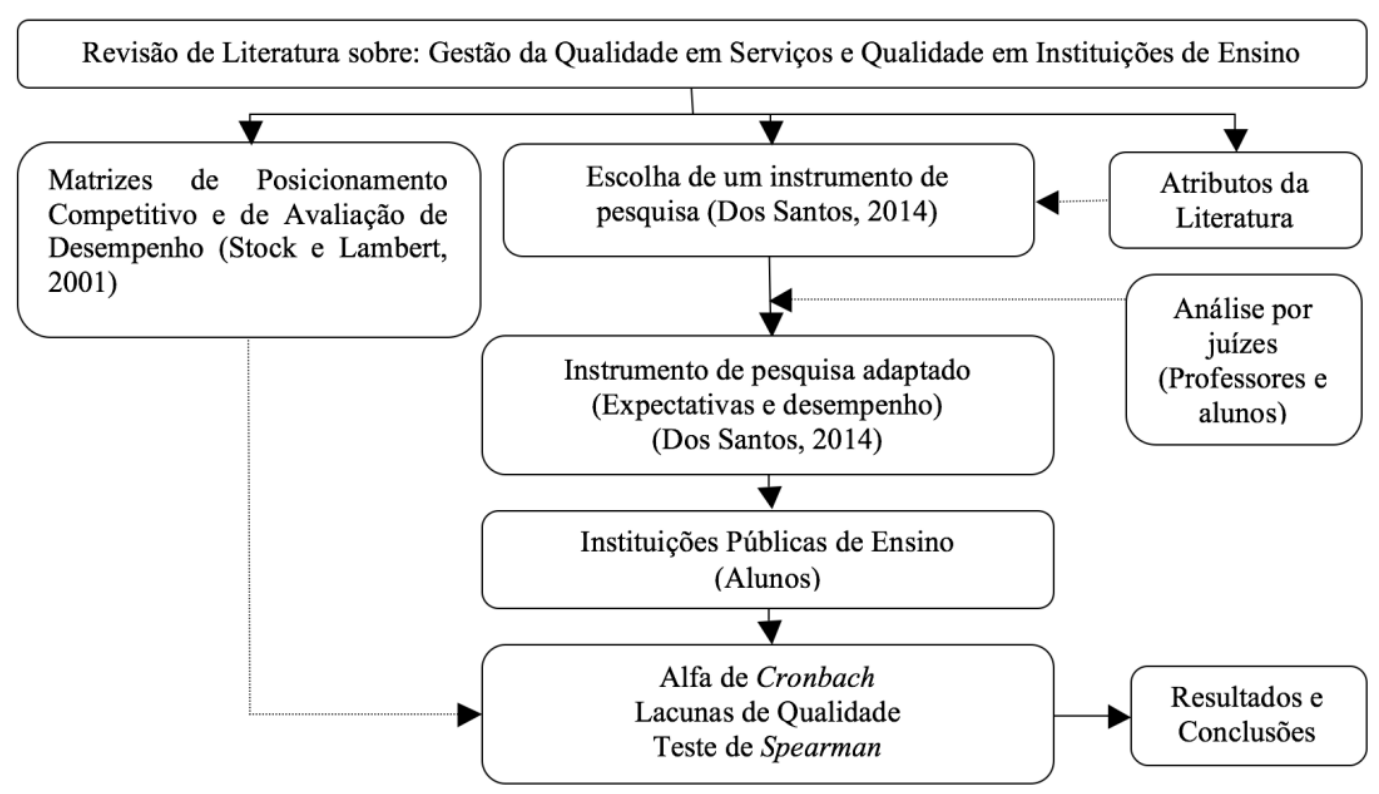

Figura 3. Design metodológico

Fonte: Elaborada pelos autores.

A ferramenta elaborada por Dos Santos (2014) foi escolhida, pois englobava os atributos mais citados nos estudos empíricos sobre qualidade (quadro 1) e que melhor descreviam os serviços pedagógicos. Porém, alguns ajustes faziam-se necessários uma vez que o seu desenvolvimento foi originário do contexto de universidades privadas. O passo inicial foi comparar as 33 variáveis embrionárias do instrumento de pesquisa selecionado com o rol de atributos mais citados na literatura. Esse filtro reduziu para 29 itens. Em seguida, submeteu-se essas variáveis ao crivo de 51 sujeitos (professores e alunos), sendo três examinadores de cada instituição de ensino, os quais foram selecionados por conveniência e acessibilidade. Estes executaram a função de juízes, analisando os níveis de clareza das sentenças que definiam cada variável, bem como opinaram sobre a irrelevância dos itens. Apontaram não só quais atributos deveriam ser excluídos por não fazer parte do contexto do ensino público, bem como propuseram certas reformulações nos termos usados a fim de adequar a linguagem ao cenário local. 
Após esse procedimento, o instrumento de pesquisa adaptado contemplou 18 variáveis. Foi empregado o alfa de Cronbach para avaliar se a escala reformulada manteve-se válida.

A aplicação do questionário foi conduzida com alunos de dezessete escolas públicas situadas no sertão paraibano e adjacências. A escolha das instituições obedeceu a critérios de conveniência e acessibilidade. Por findar, uma avaliação das expectativas (importância) e das percepções do serviço recebido (desempenho) foi executada, objetivando identificar os principais déficits de qualidade e orientar os gestores sobre quais diretrizes seguir para melhorar a prestação do serviço.

\subsection{Amostra e plano de coleta}

A população da pesquisa compreende os 1967 alunos regularmente matriculados no $2^{\circ}$ ano do ensino médio de dezessete escolas do sertão paraibano e adjacências. O estudo de Ramos (2015) respalda a escolha por esse público. Adotando-se um erro de 5\% e um nível de confiança de 95\%, a amostra atingiu a grandeza de 1351 alunos (tabela 2).

As amostras foram calculadas por escola, de forma independente, considerando o número de matriculados em cada uma delas, na série sobredita. Contudo, para resguardar de perdas de dados (missing values), planejou-se a amostra com margem de segurança de $5 \%$. Foram considerados válidos 1394 questionários, com todas as questões assinaladas com apenas uma única resposta.

Tabela 2. Amostra

\begin{tabular}{|c|c|c|c|c|}
\hline ESCOLA (SIGLA) & MUNICÍPIO & UNIVERSO & Amostra & $\begin{array}{l}\text { QUANTIDAD } \\
\text { E PLANEJADA }\end{array}$ \\
\hline Instituição de Ensino 1 (IE1) & Igaracy/PB & 72 & 61 & 64 \\
\hline Instituição de Ensino 2 (IE2) & Patos/PB & 55 & 49 & 52 \\
\hline Instituição de Ensino 3 (IE3) & $\begin{array}{l}\text { São } \\
\text { Mamede/PB }\end{array}$ & 73 & 62 & 66 \\
\hline Instituição de Ensino 4 (IE4) & Teixeira/PB & 101 & 81 & 85 \\
\hline Instituição de Ensino 5 (IE5) & Malta/PB & 178 & 122 & 128 \\
\hline Instituição de Ensino 6 (IE6) & Parelhas/RN & 132 & 99 & 104 \\
\hline Instituição de Ensino 7 (IE7) & Patos/PB & 36 & 33 & 35 \\
\hline Instituição de Ensino 8 (IE8) & Patos/PB & 34 & 32 & 34 \\
\hline Instituição de Ensino 9 (IE9) & Patos/PB & 73 & 62 & 66 \\
\hline Instituição de Ensino 10 (IE10) & Patos/PB & 103 & 82 & 87 \\
\hline Instituição de Ensino 11 (IE11) & Pombal/PB & 258 & 155 & 163 \\
\hline Instituição de Ensino 12 (IE12) & Patos/PB & 44 & 40 & 42 \\
\hline Instituição de Ensino 13 (IE13) & $\begin{array}{l}\text { Água } \\
\text { Branca/PB }\end{array}$ & 145 & 106 & 111 \\
\hline Instituição de Ensino 14 (IE14) & Desterro/PB & 16 & 16 & 16 \\
\hline Instituição de Ensino 15 (IE15) & Patos/PB & 483 & 215 & 226 \\
\hline Instituição de Ensino 16 (IE16) & Patos/PB & 94 & 76 & 80 \\
\hline Instituição de Ensino 17 (IE 17) & Teixeira/PB & 70 & 60 & 63 \\
\hline Total & & 1967 & 1351 & 1423 \\
\hline
\end{tabular}

Fonte: Pesquisa (2016).

Os respondentes foram abordados em sala de aula. A aplicação ocorreu nos três turnos por uma equipe devidamente treinada, resguardando os horários de funcionamento das instituições. No momento da aplicação foram realizados os seguintes procedimentos: 
apresentação do pesquisador; relato sobre o propósito da pesquisa; leitura em voz alta, por duas vezes, de cada sentença; oferta de tempo para responder cada sentença (aproximadamente 60 segundos) e a prestação de esclarecimentos, quando necessário.

\subsection{Atributos e instrumento de pesquisa}

A tabela 3 enumera os dezoito atributos utilizados e já com as reformulações e apontamentos feitos pelos juízes (professores e alunos).

Tabela 3. Atributos usados no instrumento de pesquisa

V1. Conhecimento prático dos professores

V2. Didática dos professores

V3. Pontualidade dos professores

V4. Estímulo e motivação oferecidos pelo professor ao aluno para a aprendizagem

V5. Disponibilidade e qualidade do acervo bibliográfico (quantidade e qualidade)

V6. Qualidade do material didático disponibilizado

V7. Facilidade de acesso e relacionamento com os professores

V8. Horário e dias em que as aulas acontecem

V9. Facilidade de acesso e relacionamento com a direção da escola

V10. Acesso à internet através de rede sem fio (wi-fi)

V11. Serviços administrativos disponibilizados aos alunos pela escola (acesso a documentos, resultados de notas, planos de ensino, serviços da biblioteca, requerimentos, entre outros)

V12. Cumprimento de prazos administrativos e acadêmicos

V13. Quantidade e qualidade dos recursos multimídia disponíveis em salas de aula (projetor, computador, TV, som, entre outros)

V14. Conforto ambiental da sala de aula (climatização, acústica, iluminação, espaço)

V15. Limpeza e manutenção das salas de aulas, banheiros, corredores e outros espaços

V16. Segurança nas instalações, inclusive no entorno da instituição

V17. Atenção, cordialidade e presteza do pessoal administrativo

V18. Reputação e credibilidade da instituição

Fonte: Elaborada pelos autores.

O instrumento de pesquisa utilizado foi um questionário estruturado, composto por três seções. A primeira contemplou questões sócio-demográficas e motivacionais. Nas seções subsequentes, os respondentes foram interrogados sobre o grau de importância e o desempenho percebido da instituição a qual está matriculado, considerando atributo a atributo. Para os últimos dois módulos, as respostas foram capturadas mediante a utilização de uma escala Likert de 11 pontos, variando de zero (não importante/péssimo desempenho) a dez (muito importante/excelente desempenho).

Ademais, a realização do teste alfa de Cronbach apontou para um índice de 0,943 o que demonstra que a escala, mesmo reduzida e reformulada, manteve o seu poder de validação.

\section{Apresentação e discussão dos resultados}

Os resultados reproduzem a apuração de 1394 respostas válidas. A tabela 4 ilustra os aspectos sociodemográficos e motivacionais dos respondentes.

Em sua maioria, os respondentes são mulheres (55,66\%), são jovens com menos de 18 anos $(88,69 \%)$, possuem renda familiar de até 5 salários mínimos (96,20\%), moram na mesma cidade em que estudam (93,25\%) e afirmaram ter escolhido a escola a qual estão 
matriculados motivados, principalmente, pelo quão cômodo é a localização do estabelecimento $(30,15 \%)$ e pela credibilidade e reputação que a imagem institucional positiva proporciona $(23,54 \%)$.

Tabela 4. Aspectos sociodemográficos e motivacionais dos respondentes

\begin{tabular}{llc}
\hline \multicolumn{2}{c}{ ASPECTOS SOCIODEMOGRÁFICOS E MOTIVACIONAIS } & $\%$ \\
\hline \multirow{2}{*}{ Gênero } & Masculino & 44,34 \\
& Feminino & 55,66 \\
\hline \multirow{2}{*}{ Faixa Etária (Anos) } & $<18$ & 88,69 \\
& $18-25$ & 10,26 \\
& $26-33$ & 0,77 \\
& $34-41$ & 0,14 \\
Renda Familiar (SM) & $42-49$ & 0,07 \\
& $>49$ & 0,07 \\
\hline \multirow{2}{*}{ Residência } & $<2$ & 66,76 \\
& $2-5$ & 29,44 \\
& $6-10$ & 2,39 \\
& $11-20$ & 0,70 \\
& $>20$ & 0,70 \\
\hline \multirow{3}{*}{ Motivação } & Mesmo Município & 93,25 \\
& Município Diferente & 6,75 \\
\hline & Proximidade c/ residência & 30,15 \\
& Professores & 9,84 \\
& Hor. Aulas & 4,36 \\
& Indicação & 18,90 \\
& Imagem & 23,54 \\
& Outros & 13,21 \\
\hline
\end{tabular}

Fonte: Pesquisa (2016).

\subsection{Importância dos atributos}

A tabela 5 revela a ordem de importância dos atributos, conforme julgamentos dos alunos de cada escola. As posições nos rankings foram definidas a partir dos valores nominais médios. Para auxiliar a análise, os atributos foram classificados em famílias, a depender da posição no ranking de importância estabelecido pelo conjunto geral das respostas. Os seis atributos que obtiveram as maiores médias formaram a família dos mais importantes; ao passo que os seis últimos integraram a família dos menos importantes. Tomando escola por escola, percebe-se que nenhum dos dezoito atributos situou-se em famílias semelhantes. Houve flutuação de atributos de uma família para outra. Por exemplo, a didática $(\mathrm{V} 2)$, para a escola IE3 $\left(4^{\circ}\right)$, faz parte da família dos mais importantes. No entanto, para escola IE8 $\left(9^{\circ}\right)$, o atributo em comento integra a faixa dos medianamente importantes.

Os atributos conhecimento (V1) e estímulo (V4) ofertados pelos docentes, em geral, figuraram no bloco dos mais importante, salvo nas escolas IE8, IE9, IE10 e IE 16. Isso coaduna com os achados de Tumino e Poitevin (2013), os quais asseveram que o nível de competência, atitudes e comportamentos do corpo docente representam os itens mais valorados pelos estudantes de universidades privadas com atuação na Argentina. No mais, ao examinar sob o prisma do ranking geral, nota-se que os docentes representam uma figura essencial na prestação do serviço, pois quatro atributos voltados 
especificamente para sua avaliação (V1, V2, V3 e V4) pertenceram ao terço dos mais importantes. Isso corrobora os achados de Dos Santos (2014).

No que tange aos menos relevantes, itens atinentes à infraestrutura sobressaíram. A qualidade do acervo bibliográfico (V5), os recursos multimídias disponíveis (V13), o acesso à internet (V10) e o conforto ambiental das salas localizaram-se, com frequência, na família dos menos importantes. A prioridade dos alunos para esses quesitos não é tão expressiva. A internet (V10), verbi gratia, só não ocupou a última posição nos seguintes estabelecimentos de ensino: IE1 $\left(5^{\circ}\right)$, IE4 $\left(17^{\circ}\right)$, IE7 $\left(17^{\circ}\right)$, IE13 $\left(5^{\circ}\right), \operatorname{IE} 16\left(17^{\circ}\right)$ e IE17 $\left(16^{\circ}\right)$. Conclusões símiles também foram ofertadas no estudo de Tumino e Poitevin (2013). Segundo esses autores, as instalações e equipamentos são pouco relevantes para a qualidade do serviço oferecido pelas universidades argentinas.

Acrescenta-se ainda que, na perspectiva geral, os escores médios obtidos oscilaram de 8,65 (conhecimento dos docentes) a 6,56 (acesso à internet), situando-se todos na faixa de medianamente a muito importante.

Finalmente, o teste de correlação de Spearman foi empregado para verificar o alinhamento entre os rankings de importância, os quais foram obtidos pelo ordenamento decrescente das médias. Revela em que medida as prioridades (expectativas) dos alunos, matriculados em diferentes escolas, são compatíveis. Para a interpretação da magnitude das relações, os Pesquisadores adotaram a seguinte classificação: $R S \leq|0,4|$ (correlação fraca), $|0,4|<\mathrm{RS}<|0,7|$ (correlação moderada) e RS $\geq|0,7|$ (correlação forte), sendo RS o coeficiente de correlação de Spearman. O resultado do teste é apresentado na tabela 6 .

Percebe-se que há um equilíbrio entre correlações significativas (com asteriscos) e nãosignificativas (sem asterisco). Portanto, não há evidências estatístiscas que sustentem a hipótese de que, independente da escola, as expectativas dos alunos do sistema público de ensino são semelhantes.

Além disso, existem indícios de que as prioridades do corpo discente das escolas IE10 e IE 16 são as menos compatíveis com as demais. Juntas concentram o maior número de relações insignificantes. Ressalta-se ainda que, quando há semelhança entre as expectativas, a intensidade transita de moderada $(0,472)$ a forte $(0,901)$.

\subsection{Qualidade do serviço}

Consoante Parasuraman, Zeithmal e Berry (1985), a qualidade do serviço é simbolizada pelas discrepâncias entre as expectativas dos clientes e suas percepções de como foi desempenhado o serviço. Portanto, para esse estudo foram apuradas as lacunas de qualidade de cada atributo, nas perspectivas geral e por escola. As lacunas (gaps) resultaram da subtração entre as médias dos desempenhos e das importâncias. Os valores negativos indicam que os alunos receberam um nível de serviço aquém do esperado, ao passo que os positivos expressam que o desempenho excedeu as expectativas. Este procedimento contribuiu para que os gestores das instituições de ensino pudessem identificar oportunidades de melhorias. 
Tabela 5. Rankings de importância geral e por escola

\begin{tabular}{|c|c|c|c|c|c|c|c|c|c|c|c|c|c|c|c|c|c|c|c|c|c|}
\hline & & ATRIBUTOS & GEF & & IE1 & IE2 & IE3 & IE4 & IE5 & IE6 & IE7 & IE8 & IE9 & IE10 & IE1 1 & IE 12 & IE13 & IE 14 & IE 15 & IE 16 & IE 17 \\
\hline & & & $\mathrm{Me}$ & $\mathrm{R}$ & & & & & & & & & $R a$ & $\operatorname{king}(\mathrm{R})$ & & & & & & & \\
\hline & & 1. Conhecim. & 8,65 & 1 & 1 & 1 & 2 & 1 & 2 & 2 & 1 & 11 & 3 & 3 & 1 & 5 & 2 & 1 & 3 & 3 & 1 \\
\hline & & 4. Estímulo & 8,53 & 2 & 2 & 4 & 1 & 2 & 1 & 3 & 5 & 3 & 10 & 17 & 3 & 4 & 3 & 2 & 2 & 10 & 6 \\
\hline & $\underset{G}{\overleftarrow{G}}$ & 15. Limpeza & 8,47 & 3 & 15 & 8 & 6 & 8 & 8 & 1 & 2 & 1 & 2 & 10 & 5 & 7 & 1 & 6 & 1 & 5 & 4 \\
\hline & 安 & 2. Didática & 8,30 & 4 & 7 & 9 & 4 & 5 & 7 & 13 & 7 & 9 & 7 & 11 & 2 & 1 & 4 & 4 & 8 & 4 & 2 \\
\hline & & 3. Pontualidad & 8,28 & 5 & 4 & 6 & 3 & 10 & 5 & 11 & 14 & 4 & 8 & 8 & 4 & 3 & 7 & 13 & 5 & 15 & 5 \\
\hline 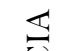 & & 18. Imagem & 8,19 & 6 & 9 & 10 & 7 & 3 & 6 & 10 & 16 & 10 & 6 & 2 & 9 & 15 & 11 & 8 & 6 & 12 & 7 \\
\hline Z & & 7. Rel.Prof. & 8,17 & 7 & 6 & 2 & 5 & 11 & 4 & 12 & 9 & 7 & 14 & 4 & 7 & 2 & 13 & 11 & 14 & 14 & 3 \\
\hline 瘏 & & 8. Horário & 8,14 & 8 & 3 & 3 & 14 & 18 & 3 & 5 & 13 & 2 & 12 & 12 & 6 & 6 & 14 & 5 & 7 & 16 & 9 \\
\hline 징 & $\overrightarrow{\widehat{a}}$ & 6. Material & 8,13 & 9 & 8 & 7 & 9 & 7 & 11 & 8 & 8 & 16 & 4 & 14 & 11 & 9 & 17 & 3 & 4 & 6 & 10 \\
\hline$\xi$ & 这 & 11. S. Admin. & 7,96 & 10 & 14 & 5 & 16 & 14 & 10 & 9 & 11 & 6 & 17 & 7 & 12 & 12 & 8 & 9 & 10 & 9 & 15 \\
\hline & & 16. Segurança & 7,94 & 11 & 17 & 13 & 13 & 4 & 15 & 7 & 4 & 13 & 13 & 15 & 15 & 11 & 9 & 17 & 9 & 7 & 8 \\
\hline & & 17. At. Admin. & 7,92 & 12 & 13 & 12 & 15 & 13 & 9 & 16 & 6 & 8 & 15 & 5 & 13 & 13 & 12 & 14 & 13 & 11 & 12 \\
\hline & & 5. Acervo & 7,87 & 13 & 11 & 15 & 12 & 9 & 12 & 17 & 18 & 15 & 11 & 9 & 8 & 14 & 18 & 15 & 12 & 13 & 11 \\
\hline & & 13. R. Multim. & 7,85 & 14 & 16 & 11 & 11 & 6 & 16 & 4 & 12 & 17 & 5 & 1 & 16 & 16 & 6 & 16 & 11 & 8 & 13 \\
\hline & $\underline{x}$ & 12. Prazos & 7,84 & 15 & 12 & 14 & 17 & 15 & 13 & 14 & 10 & 5 & 9 & 16 & 14 & 10 & 15 & 12 & 16 & 1 & 18 \\
\hline & $\underset{n}{\pi}$ & 9. Rel. Direção & 7,76 & 16 & 10 & 16 & 8 & 16 & 14 & 15 & 15 & 14 & 16 & 6 & 10 & 8 & 16 & 7 & 17 & 18 & 14 \\
\hline & & 14. C. Amb. & 7,73 & 17 & 18 & 17 & 10 & 12 & 17 & 6 & 3 & 12 & 1 & 13 & 17 & 17 & 10 & 10 & 15 & 2 & 17 \\
\hline & & 10. Internet & 6,56 & 18 & 5 & 18 & 18 & 17 & 18 & 18 & 17 & 18 & 18 & 18 & 18 & 18 & 5 & 18 & 18 & 17 & 16 \\
\hline
\end{tabular}

Nota: $\mathrm{Me}=$ média; $\mathrm{R}=$ posição do atributo no ranking.

Fonte: Pesquisa (2016) 
Tabela 6. Teste de Spearman

\begin{tabular}{|c|c|c|c|c|c|c|c|c|c|c|c|c|c|c|c|c|c|c|}
\hline & $\mathbf{G}$ & IE 1 & IE2 & IE3 & IE4 & IE5 & IE6 6 & IE7 & IE8 & IE9 & IE 10 & IE11 & IE12 & IE13 & IE14 & IE 15 & IE16 & IE17 \\
\hline$G$ & $1, \mathrm{OO}$ & , $519^{*}$ &, $827^{* * *}$ & ,761** & ,637** &, $884^{* *}$ & , $540^{*}$ & , 414 &, $577^{*}$ & ,364 & , 197 &, $882^{* * *}$ & ,734** & , 498* & , $664^{* * *}$ &, $876^{* *}$ & , 164 &, $901^{* *}$ \\
\hline IE 1 & & 1,00 &, $558^{*}$ & ,451 & ,098 &, $692^{* *}$ &,- 011 &,- 162 & ,216 &,- 110 &,- 061 &, $653^{* * *}$ &, $577^{*}$ & , 143 &, $474^{*}$ & ,323 &,- 368 &, $503^{*}$ \\
\hline IE2 & & & $1, \mathrm{OO}$ &, $534^{*}$ & ,337 &, $868^{* *}$ &, $546^{*}$ & ,311 &, $562^{*}$ &, 154 & ,282 &, $713^{* *}$ &, $703^{* *}$ & ,280 &, $606^{* * *}$ &, $686^{* * *}$ & ,032 &, $697^{* *}$ \\
\hline IE3 & & & & 1,00 &, $666^{* *}$ &, $643^{* *}$ & ,434 & ,346 & ,257 &, $494^{*}$ & ,267 &, $779^{* * *}$ &, $674^{* *}$ & ,406 &, $606^{* *}$ &, $622^{* * *}$ & ,094 &, $796^{* *}$ \\
\hline $\mathrm{IE}_{4}$ & & & & & $1, \mathrm{OO}$ & ,354 & , $498^{*}$ & ,437 &,- 069 &, $554^{*}$ & ,205 & ,426 & ,224 & , 447 & ,329 &, $668^{* * *}$ & , 426 &, $643^{* *}$ \\
\hline IE5 & & & & & & $1, \mathrm{OO}$ & ,356 & ,218 &, $680^{* *}$ & , 129 & ,236 &, $876^{* *}$ &, $750^{* *}$ & ,236 &, $651^{\text {*** }}$ &, $674^{* * *}$ &,- 084 &, $765^{* *}$ \\
\hline IE6 & & & & & & & $1, \mathrm{OO}$ &, $624^{* *}$ & ,335 &, $618^{* *}$ & 071 & ,302 & ,222 &, $511^{*}$ &, $507^{*}$ &, $711^{\text {*** }}$ & ,434 & ,383 \\
\hline IE7 & & & & & & & & $1, \mathrm{OO}$ & ,292 &, $474^{*}$ &,- 115 & 201 & ,302 &, $472^{*}$ & 410 & , 412 &, $719^{* *}$ & ,352 \\
\hline IE8 & & & & & & & & & $1, \mathrm{OO}$ & ,057 &,- 063 &, $542^{*}$ &, $581^{*}$ & ,236 & ,387 & , 441 & ,075 & ,350 \\
\hline IE9 & & & & & & & & & & $1, \mathrm{OO}$ &, 110 &, 251 & 075 & ,276 & 412 &, $534^{*}$ &, $668^{* *}$ & ,307 \\
\hline IE1O & & & & & & & & & & & $1, \mathrm{OO}$ & , 199 & ,018 &,- 005 & ,020 & ,063 &,- 148 & ,278 \\
\hline IE 11 & & & & & & & & & & & & 1,00 &, $835^{* *}$ & ,300 &, $697^{* * *}$ &, $686^{\text {** }}$ &,- 018 &, $841^{* *}$ \\
\hline IE 12 & & & & & & & & & & & & & 1,00 & , 195 &, $589^{*}$ &, $478^{*}$ & ,009 &, $742^{* *}$ \\
\hline IE13 & & & & & & & & & & & & & & 1,00 &, 185 & , 455 & ,278 & , 434 \\
\hline IE 14 & & & & & & & & & & & & & & & 1,00 &, $620^{* * *}$ & ,265 &, $482^{*}$ \\
\hline IE 15 & & & & & & & & & & & & & & & & 1,00 & ,245 &, $711^{* *}$ \\
\hline IE 16 & & & & & & & & & & & & & & & & & $1, \mathrm{OO}$ & ,036 \\
\hline IE 17 & & & & & & & & & & & & & & & & & & 1,00 \\
\hline
\end{tabular}

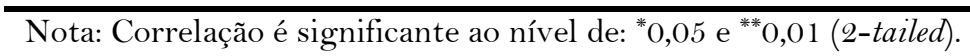

Fonte: Pesquisa (2016). 
Verificou-se, na tabela 7, uma predominância de lacunas negativas, sinalizando que o serviço oferecido pelas escolas investigadas está aquém das expectativas dos alunos. $\mathrm{O}$ desempenho das instituições sobrepujou as expectativas do alunado em, somente, 33 observações (grifadas na cor cinza) de um total de 324. Os atributos pontualidade dos professores (V3) e imagem institucional (V18) destacaram-se por concentrar o maior contingente de gaps positivos: quatro observações cada. As escolas IE7 e IE8 também sobressaíram, pois juntas detêm 20 lacunas positivas.

Dos atributos investigados, dois mostraram lacunas negativas para todas as escolas, sendo eles: estímulo ofertado pelos professores no processo de ensino-aprendizagem (V4) e qualidade do material didático (V6). Isso aponta, principalmente, a fragilidade do sistema público de ensino em termos dos recursos pedagógicos utilizados, reforçando os apontamentos de Figueroa e colaboradores. (2013); bem como ressalta os postulados de Tumino e Poitevin (2013) sobre o poder de interferência do método de ensino sobre a formação do estudante.

Além disto, a organização IE10 apresentou as maiores lacunas de qualidade, com magnitudes superiores a -3 para todos os atributos. Diante do cenário, o atributo recursos multimídias (V13) merece uma atenção especial por parte da gestão. Esse item apresenta um déficit elevado ( $2^{\circ}$ maior lacuna negativa) e é percebido como aquele mais valorizado pelos discentes da instituição $\left(1^{\circ}\right)$. Assim, ações precisam ser tomadas com urgência, conforme preconizam Stock e Lambert (2001).

\subsection{Matrizes de posicionamento competitivo e de avaliação de desempenho}

A tabela 8 apresenta os principais apontamentos ofertados pelas matrizes de posicionamento competitivo e de avaliação de desempenho. Percebe-se que o ponto de interseção entre as instituições de ensino analisadas é vazio. Todavia, há algumas variáveis que estiveram presentes em um número expressivo de instituições de ensino, tais como: internet (V10), conhecimento docente (V1), estímulo (V4) e segurança (V16).

$\mathrm{O}$ atributo internet (V10) situou-se, para a maioria dos casos, como menor fraqueza, salvo nas escolas IE1 e IE10. Configurou-se como um quesito pouco valorado pelos discentes e que a organização teve um desempenho inferior a melhor prática do mercado (benchmark). Não obstante a aparente fragilidade, sugere-se que a manutenção (MA) do desempenho das organizações seja a estratégias mais apropriada para o atributo em comento. Na maior fração das observações, evidenciou-se esse fenômeno. Não é salutar reconfigurar os recursos e capacidades das escolas a fim de aperfeiçoar o desempenho em um item fora do escopo de prioridades mais urgentes. Provavelmente, o posicionamento desse item na família dos menos importantes esteja atrelado as arguições de Alves (2009). Para a autora, os docentes pouco exploram em termos pedagógicos as Tecnologias de Informação e Comunicação dentro da sala de aula.

Quanto aos atributos conhecimento docente (V1) e estímulo (V4), para a maioria, estes quesitos foram vistos como maior força, exceto para a IE10. Revelaram-se atributos altamente valorizados pelos alunos e em que a escola possui um desempenho satisfatório frente aos rivais. 
Tabela 7. Lacunas de qualidade

\begin{tabular}{|c|c|c|c|c|c|c|c|c|c|c|c|c|c|c|c|c|c|c|c|c|c|}
\hline \multirow{20}{*}{ 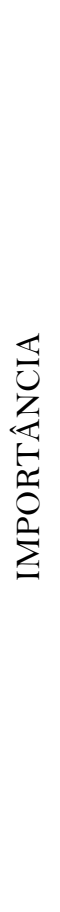 } & & \multirow{2}{*}{ Atr. } & \multicolumn{2}{|c|}{ Geral } & 1 & 82 & E3 & E4 & E5 & $E 6$ & E7 & IE8 & IE9 & IE10 & E11 & E12 & IE 13 & IE 14 & IE 15 & IE 16 & IE 17 \\
\hline & & & Lac. & $\mathrm{R}$ & \multicolumn{17}{|c|}{ Lacunas de Qualidade } \\
\hline & \multirow{6}{*}{ 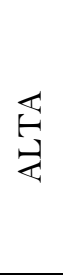 } & V1 & $-0,67$ & 1 & $-0,32$ & $-0,25$ & $-0,48$ & $-1,01$ & $-0,37$ & $-1,03$ & $-0,39$ & 0,27 & $-0,15$ & $-3,78$ & $-0,52$ & $-0,29$ & $-0,77$ & $-0,53$ & $-0,25$ & $-0,64$ & $-0,13$ \\
\hline & & $\mathrm{V}_{4}$ & $-0,85$ & 2 & $-0,40$ & $-0,75$ & $-0,77$ & $-1,35$ & $-0,97$ & $-1,12$ & $-0,40$ & $-0,10$ & $-0,52$ & $-3,05$ & $-0,56$ & $-0,31$ & $-0,76$ & $-0,59$ & $-0,81$ & $-0,53$ & $-0,14$ \\
\hline & & $\mathrm{V} 15$ & $-1,24$ & 3 & $-0,11$ & $-1,67$ & $-1,89$ & $-3,71$ & $-1,40$ & $-1,32$ & 0,17 & $-0,35$ & $-0,32$ & $-3,75$ & $-0,72$ & $-0,26$ & $-1,68$ & $-1,06$ & $-0,64$ & $-0,54$ & $-0,62$ \\
\hline & & $\mathrm{V}_{2}$ & $-0,66$ & 4 & $-0,41$ & $-0,42$ & $-0,70$ & $-1,04$ & $-0,33$ & $-0,77$ & 0,03 & 0,10 & $-0,26$ & $-3,70$ & $-0,44$ & $-1,50$ & $-0,51$ & 0,01 & $-0,11$ & $-0,65$ & $-0,55$ \\
\hline & & V3 & $-0,62$ & 5 & $-0,25$ & $-1,12$ & $-0,48$ & $-0,66$ & $-0,63$ & $-0,79$ & 0,74 & 0,23 & $-0,21$ & $-3,49$ & $-0,60$ & $-0,24$ & $-0,23$ & 0,35 & $-0,56$ & 0,07 & $-0,48$ \\
\hline & & V18 & $-0,58$ & 6 & $-0,13$ & $-1,27$ & $-0,38$ & $-2,62$ & $-0,95$ & $-0,69$ & 0,36 & $-0,02$ & 0,23 & $-3,44$ & 0,15 & 0,52 & $-0,33$ & $-0,06$ & $-0,08$ & $-0,14$ & $-0,25$ \\
\hline & \multirow{6}{*}{ 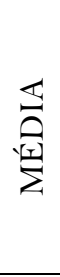 } & V7 & $-0,72$ & 7 & $-0,27$ & 0,81 & $-0,33$ & $-1,68$ & $-0,63$ & $-1,23$ & 0,34 & 0,37 & $-0,67$ & $-4,17$ & $-0,42$ & $-1,43$ & $-0,32$ & $-0,13$ & $-0,27$ & $-0,51$ & $-0,39$ \\
\hline & & V8 & $-0,55$ & 8 & $-0,37$ & $-0,69$ & $-0,73$ & $-1,74$ & $-0,48$ & $-0,58$ & 0,51 & $-0,39$ & $-0,29$ & $-3,44$ & $-0,07$ & $-0,69$ & $-0,02$ & $-0,63$ & $-0,11$ & $-0,40$ & 0,29 \\
\hline & & V6 & $-0,97$ & 9 & $-0,62$ & $-1,35$ & $-0,71$ & $-2,89$ & $-0,73$ & $-0,96$ & $-0,14$ & $-2,29$ & $-0,18$ & $-3,23$ & $-0,75$ & $-0,24$ & $-0,71$ & $-0,71$ & $-0,51$ & $-0,73$ & $-0,28$ \\
\hline & & V11 & $-1,18$ & 10 & $-0,73$ & $-1,58$ & $-1,71$ & $-2,95$ & $-1,08$ & $-1,58$ & 0,26 & $-0,02$ & $-0,18$ & $-3,56$ & $-0,65$ & $-1,07$ & $-0,95$ & $-1, \mathrm{OO}$ & $-0,93$ & $-0,69$ & $-0,47$ \\
\hline & & V16 & $-1,26$ & 11 & $-0,38$ & $-1,67$ & $-1,45$ & $-4,18$ & $-0,73$ & $-1,54$ & $-0,18$ & 0,03 & $-0,09$ & $-3,40$ & $-0,87$ & $-0,24$ & $-1,31$ & $-0,61$ & $-0,96$ & $-0,77$ & $-1,18$ \\
\hline & & V17 & $-0,95$ & 12 & $-0,29$ & $-1,13$ & $-1,05$ & $-3,15$ & $-0,87$ & $-1,09$ & $-0,23$ & $-0,57$ & $-0,18$ & $-3,74$ & $-0,50$ & 0,29 & $-0,63$ & $-0,23$ & $-0,58$ & $-0,54$ & $-0,47$ \\
\hline & \multirow{6}{*}{ 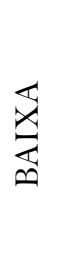 } & V5 & $-0,79$ & 13 & $-0,33$ & $-1,08$ & $-0,58$ & $-2,36$ & $-0,61$ & $-1,03$ & 0,14 & 0,29 & $-0,45$ & $-3,36$ & $-0,58$ & $-0,19$ & $-0,45$ & $-0,41$ & $-0,30$ & $-0,48$ & $-0,77$ \\
\hline & & V13 & $-1,21$ & 14 & 0,43 & $-1,65$ & $-2,12$ & $-3,54$ & $-0,76$ & $-1,64$ & 0,29 & $-0,64$ & $-0,09$ & $-4,11$ & $-0,77$ & 0,01 & $-1,31$ & 0,01 & $-1,02$ & $-0,35$ & $-0,88$ \\
\hline & & V12 & $-0,85$ & 15 & $-0,48$ & $-1,04$ & $-0,80$ & $-2,04$ & $-0,26$ & $-1,35$ & 0,01 & 0,13 & $-0,29$ & $-3,10$ & $-0,61$ & $-0,55$ & $-0,46$ & $-0,88$ & $-0,45$ & $-1,84$ & $-0,06$ \\
\hline & & V9 & $-0,86$ & 16 & $-0,32$ & $-0,44$ & $-1,29$ & $-2,49$ & $-0,44$ & $-1,32$ & $-0,14$ & 0,39 & $-0,48$ & $-3,71$ & $-0,54$ & $-0,88$ & $-0,37$ & $-0,06$ & $-0,40$ & $-0,74$ & $-0,34$ \\
\hline & & V14 & $-1,87$ & 17 & $-0,11$ & $-1,31$ & $-2,33$ & $-5,29$ & $-1,86$ & $-3,03$ & $-0,20$ & 0,03 & $-0,23$ & $-3,46$ & $-1,42$ & $-0,50$ & $-1,94$ & $-0,82$ & $-1,98$ & $-0,93$ & $-1,66$ \\
\hline & & V10 & $-1,88$ & 18 & $-0,02$ & $-1,62$ & $-3,03$ & $-4,29$ & $-1,44$ & $-2,79$ & $-0,69$ & 0,26 & $-0,89$ & $-3,22$ & $-1,22$ & 0,36 & $-1,59$ & $-2,29$ & $-1,90$ & $-2,64$ & $-2,44$ \\
\hline
\end{tabular}

Legenda: $\mathrm{R}=$ posição do atributo no ranking.

Fonte: Pesquisa (2016). 
Para o conhecimento docente (V1), tomando escola por escola, as ações indicadas foram semelhantes. Alvitra-se que as instituições mantenham ou melhorem (MM) os seus desempenhos nesse ponto. Para tanto, os gestores, por exemplo, podem desenvolver um plano de capacitação que incentive à participação em feiras, congressos, simpósio e outros eventos de cunho científico. Por outro lado, na IE10, o know-how dos professores foi constatado como a maior fraqueza organizacional. Como que esse item é de extrema relevância para os alunos e que há outras escolas no mercado que tem desempenho superiores, recomenda-se, em caráter de urgência, a implementação de ações de melhorias no nível de serviço ofertado.

Já no que concerne ao estímulo (V4), a indicação de manter ou melhorar (MM) notabilizou-se. No IE13, o apontamento foi distinto. Para esse caso, a melhoria é necessária. O desempenho da escola nesse atributo não está condizente com o nível das expectativas dos seus alunos. Para a escola IE10, o estímulo dos docentes é percebido como menor força por integrar a família dos menos importantes $\left(17^{\circ}\right)$. Aconselha-se reduzir ou manter o nível de serviço que está sendo prestado.

Por sua vez, a segurança (V16) foi apontada em oito escolas, as quais sejam: IE1, IE2, IE3, IE4, IE7, IE9, IE11 e IE14. Em maior parte, ocupou a categoria menor fraqueza, sendo enquadrada dentre os atributos menos importantes. Contudo, os casos das instituições IE4 e IE7 chamaram atenção. Na primeira, esse quesito foi visto como maior fraqueza. Mesmo integrando o grupo dos mais importantes, o desempenho organizacional nesse item estava muito abaixo das práticas de seus concorrentes. Mostra-se uma situação de vulnerabilidade competitiva, exigindo dos gestores ações urgentes de melhorias (MD). Investigar os motivos que geram a sensação de insegurança nos alunos pode ser uma das atitudes embrionárias a implementar-se. Para a IE7, esse atributo é visto como maior força, inclusive sendo recomendado a manutenção ou melhoria (MM) do atual nível de serviço prestado.

No mais, é oportuno executar uma análise individualizada. Atributos relacionados a aspectos físicos merecem atenção dos gestores, tais como: limpeza (V15), recursos multimídias (V13), conforto ambiental (V14) e material didático (V6). Em suma, constituem-se como maior fraqueza e, por essa razão, precisam ser fortalecidos. Distinguem-se tão somente pelo grau de priorização das ações de melhorias. Os administradores das escolas IE3, IE4, IE10 e IE13 precisam aperfeiçoar, imediatamente, os desempenhos (MD), sob pena de gerar insatisfação nos discentes. Já para as organizações IE6, IE14 e IE16 melhorias também são necessárias, porém em uma gradação menor de urgência.

Enfim, foi possível extrair um conjunto maior de ações, com fulcro na combinação das matrizes propostas por Stock e Lambert (2001). Esses apontamentos podem subsidiar às decisões gerenciais de aperfeiçoamento das estratégias de qualidade de cada escola, uma vez que a compreensão das forças, fraquezas organizacionais e atributos a serem melhorados serão conhecidos. Por exemplo, se uma escola tem alto déficit de qualidade na didática de seus professores e, nesse ponto, o seu desempenho é bem inferior a instituições concorrentes; há fortes indícios de que ações de melhorias devem ser postas em prática com urgência. Em síntese, a gestão deve investir em capacitações que melhor qualifiquem os docentes. Seria um item que deve ser apreciado pela direção da escola com um grau de prioridade elevado. 
Tabela 8. Ações indicadas pelas matrizes de posicionamento competitivo e de avaliação de desempenho

\begin{tabular}{|c|c|c|c|c|c|c|c|c|}
\hline ATRIBUTO & MPC & MAD & ATRIBUTO & MPC & MAD & ATRIBUTO & MPC & MAD \\
\hline IEI & & & IE2 & & & IE3 & & \\
\hline V1. Conhec. Docente & Maior Força & MM & V1. Conhec. Docente & Maior Força & MM & V4. Estímulo & Maior Força & MM \\
\hline V4. Estímulo & Maior Força & MM & V7. Rel. Professores & Maior Força & MM & V1. Conhec. Docente & Maior Força & MM \\
\hline V8. H. das Aulas & Maior Força & MM & V8. H. das Aulas & Maior Força & MM & V3. Pontualidade & Maior Força & MM \\
\hline V3. Pontualidade & Maior Força & MM & V4. Estímulo & Maior Força & MM & V2. Didática & Maior Força & MM \\
\hline V10. Internet & Maior Força & MM & V16. Segurança & Menor Fraqueza & MA & V7. Rel. Professores & Maior Força & MM \\
\hline V7. Rel. Professores & Maior Força & MM & V9. Rel. Direção & Menor Força & $\mathrm{RM}$ & V15. Limpeza & Maior Fraqueza & MD \\
\hline V15. Limpeza & Menor Fraqueza & MA & V14. Conf. Ambiental & Menor Fraqueza & MA & V16. Segurança & Menor Fraqueza & MA \\
\hline V13. R. Multimídias & Menor Fraqueza & MA & V10. Internet & Menor Fraqueza & MA & V11. Serv. Administ. & Menor Fraqueza & MA \\
\hline V16. Segurança & Menor Fraqueza & MA & & & & V10. Internet & Menor Fraqueza & MA \\
\hline V 14. Conf. Ambiental & Menor Fraqueza & MA & & & & & & \\
\hline$I E 4$ & & & IE5 & & & IE6 & & \\
\hline V1. Conhec. Docente & Maior Força & MM & V4. Estímulo & Maior Força & MM & V15. Limpeza & Maior Força & MM \\
\hline V4. Estímulo & Maior Força & MM & V1. Conhec. Docente & Maior Força & MM & V1. Conhec. Docente & Maior Força & MM \\
\hline V16. Segurança & Maior Fraqueza & DM & V8. H. das Aulas & Maior Força & MM & V4. Estímulo & Maior Força & MM \\
\hline V2. Didática & Maior Força & MM & V7. Rel. Professores & Maior Força & MM & V13. R. Multimídias & Maior Fraqueza & $\mathrm{ME}$ \\
\hline V13. R. Multimídias & Maior Fraqueza & MD & V3. Pontualidade & Maior Força & MM & V8. H. das Aulas & Maior Força & MM \\
\hline V17. Atend. Administ. & Menor Fraqueza & MA & V18. Imagem & Maior Fraqueza & ME & V14. Conf. Ambiental & Maior Fraqueza & MD \\
\hline \multirow[t]{4}{*}{ V10. Internet } & Menor Fraqueza & MA & V9. Rel. Direção & Menor Força & $\mathrm{RM}$ & V2. Didática & Menor Força & $\mathrm{RM}$ \\
\hline & & & V13. R. Multimídias & Menor Fraqueza & MA & V12. Prazos & Menor Fraqueza & MA \\
\hline & & & V14. Conf. Ambiental & Menor Fraqueza & MA & V10. Internet & Menor Fraqueza & MA \\
\hline & & & V10. Internet & Menor Fraqueza & MA & & & \\
\hline IE7 & & & $I E 8$ & & & IE9 & & \\
\hline V15. Limpeza & Maior Força & MM & V15. Limpeza & Maior Força & MM & V14. Conf. Ambiental & Maior Força & MM \\
\hline V14. Conf. Ambiental & Maior Fraqueza & MM & V8. H. das Aulas & Maior Força & MM & V1. Conhec. Docente & Maior Força & MM \\
\hline V16. Segurança & Maior Força & MM & V4. Estímulo & Maior Força & MM & V6. Mat. Didático & Maior Força & MM \\
\hline V17. Atend. Administ. & Maior Força & $\mathrm{ME}$ & V11. Serv. Administ. & Maior Força & $\mathrm{ME}$ & V13. R. Multimídias & Maior Força & MM \\
\hline V8. H. das Aulas & Menor Força & $\mathrm{RM}$ & V9. Rel. Direção & Menor Força & $\mathrm{RM}$ & V18. Imagem & Maior Força & MM \\
\hline V18. Imagem & Menor Fraqueza & MA & V6. Mat.Didático & Menor Fraqueza & MA & V16. Segurança & Menor Força & $\mathrm{RM}$ \\
\hline V10. Internet & Menor Fraqueza & MA & V13. R. Multimídias & Menor Fraqueza & MA & V7. Rel. Professores & Menor Fraqueza & MA \\
\hline \multirow[t]{2}{*}{ V5. Ac. Bibliográfico } & Menor Fraqueza & MA & V10. Internet & Menor Fraqueza & MA & V9. Rel. Direção & Menor Fraqueza & MA \\
\hline & & & & & & V10. Internet & Menor Fraqueza & MA \\
\hline
\end{tabular}




\begin{tabular}{|c|c|c|c|c|c|c|c|c|}
\hline IE10 & & & IE 11 & & & IE12 & & \\
\hline V13. R. Multimídias & Maior Fraqueza & MD & V2. Didática & Maior Força & MM & V2. Didática & Maior Fraqueza & $\mathrm{ME}$ \\
\hline V18. Imagem & Maior Fraqueza & MM & V4. Estímulo & Maior Força & $\mathrm{MM}$ & Vs. Pontualidade & Maior Força & MM \\
\hline V1. Conhec. Docente & Maior Fraqueza & MD & V8. H. das Aulas & Maior Força & $\mathrm{MM}$ & V4. Estímulo & Maior Força & MM \\
\hline V9. Rel. Direção & Maior Força & MD & V12. Prazos & Men. Fraqueza & MA & V1. Conhec. Docente & Maior Força & MM \\
\hline V14. Conf. Ambient. & Men. Fraqueza & $\mathrm{RM}$ & V16. Segurança & Men. Fraqueza & MA & V8. H. das Aulas & Maior Força & $\mathrm{ME}$ \\
\hline V12. Prazos & Menor Força & $\mathrm{RM}$ & V13. R. Multimídias & Men. Fraqueza & MA & V17. Atend. Administ. & Men. Força & $\mathrm{RM}$ \\
\hline V4. Estímulo & Menor Força & $\mathrm{RM}$ & V14. Conf. Ambient. & Men. Fraqueza & MA & V13. R. Multimídias & Men. Fraqueza & $\mathrm{RM}$ \\
\hline V10. Internet & Menor Força & $\mathrm{RM}$ & V10. Internet & Men. Fraqueza & MA & V14. Conf. Ambiental & Men. Fraqueza & MA \\
\hline IE13 & & & IE14 & & & IE 15 & & \\
\hline V15. Limpeza & Maior Fraqueza & MD & V1. Conhec. Docente & Maior Força & MM & V15. Limpeza & Maior Força & MM \\
\hline V4. Estímulo & Maior Força & ME & V4. Estímulo & Maior Força & MM & V4. Estímulo & Maior Força & $\mathrm{ME}$ \\
\hline V13. R. Multimídias & Maior Fraqueza & MD & V2. Didática & Maior Força & MM & V1. Conhec. Docente & Maior Força & MM \\
\hline V7. Rel. Professores & Men. Força & $\mathrm{RM}$ & V15. Limpeza & Maior Fraqueza & ME & V17. Atend. Administ. & Men. Fraqueza & $\mathrm{RM}$ \\
\hline V8. H. das Aulas & Men. Força & $\mathrm{RM}$ & V3. Pontualidade & Men. Força & $\mathrm{RM}$ & V14. Conf. Ambiental & Men. Fraqueza & MA \\
\hline V9. Rel. Direção & Men. Força & $\mathrm{RM}$ & V13. R. Multimídias & Men. Fraqueza & $\mathrm{RM}$ & V12. Prazos & Men. Fraqueza & $\mathrm{RM}$ \\
\hline V6. Mat. Didático & Men. Fraqueza & MA & V16. Segurança & Men. Fraqueza & MA & V10. Internet & Men. Fraqueza & MA \\
\hline & & & V10. Internet & Men. Fraqueza & MA & & & \\
\hline IE 16 & & & IE 17 & & & \multirow{10}{*}{\multicolumn{3}{|c|}{$\begin{array}{l}\text { Legenda: MAD: matriz de avaliação de desempenho, MPC: } \\
\text { matriz de posicionamento competitivo, MD: melhorar } \\
\text { definitivamente, ME: melhorar MM: manter ou melhorar, } \\
\text { MA: manter, RM: reduzir ou manter }\end{array}$}} \\
\hline V14. Conf. Ambient. & Maior Fraqueza & MM & V1. Conhec. Docente & Maior Força & MM & & & \\
\hline V1. Conhec. Docente & Maior Força & MM & V2. Didática & Maior Força & MM & & & \\
\hline V2. Didática & Maior Força & MM & V7. Rel. Professores & Maior Força & MM & & & \\
\hline V6. Mat. Didático & Maior Fraqueza & ME & V3. Pontualidade & Maior Força & $\mathrm{MM}$ & & & \\
\hline V5. Ac. Bibliográfico & Men. Força & $\mathrm{RM}$ & V4. Estímulo & Maior Força & MM & & & \\
\hline V8. H. das Aulas & Men. Fraqueza & MA & V13. R. Multimídias & Men. Fraqueza & MA & & & \\
\hline V10. Internet & Men. Fraqueza & MA & V10. Internet & Men. Fraqueza & MA & & & \\
\hline \multirow[t]{2}{*}{ V9. Rel. Direção } & Men. Fraqueza & MA & V14. Conf. Ambient. & Men. Fraqueza & MA & & & \\
\hline & & & V12. Prazos & Men. Fraqueza & MA & & & \\
\hline
\end{tabular}

Fonte: Pesquisa (2016). 


\section{Considerações finais}

Este artigo propôs uma discussão acerca da qualidade do serviço prestado no sistema público de ensino. Para isto, os alunos de dezessete instituições avaliaram as dissonâncias entre os serviços esperado (expectativas) e recebido (desempenho percebido). Dentre os achados, constatou-se que o padrão de expectativas dos alunos, em essência, foi heterogêneo. Alunos matriculados em diferentes escolas atribuem prioridades pouco ou nada semelhante para um conjunto de 18 atributos, conforme apontam os coeficientes de correlação de Spearman. Enquanto alunos de uma escola valoram certos atributos do serviço, em outro ambiente escolar situado na mesma região geográfica, os discentes conferem maior importância a outros itens. Assim, os gestores precisam conhecer as reais necessidades e desejos do alunado para poder gerir os recursos de modo mais eficiente.

Em geral, a figura do docente ocupou posição de destaque na prestação do serviço educacional, com os atributos conhecimento e o estímulo integrando a família dos mais importantes. Reforça, assim, os apontamentos de Tumino e Poitevin (2013) e Dos Santos (2014). Além disso, essas variáveis, na maioria dos casos, também foram percebidas como maior força e com indicação para implementar ações que mantivessem ou melhorassem o desempenho organizacional. Já dentre os menos valorados, os itens relativos à infraestrutura (por exemplo, internet e segurança) sobressaíram. Nessa direção, Radons e colaboradores (2012) asseguram que os aspectos físicos não interferem na satisfação dos alunos com os serviços prestados em um ambiente escolar.

Detectou-se ainda uma predominância de lacunas negativas, indicando que o serviço oferecido pelas escolas públicas investigadas está aquém das expectativas dos clientes. Isso ratifica os achados de Ramos (2015), quando relata sobre a ineficácia do ensino das escolas públicas brasileiras. Vale destacar que a escola IE10 foi a que apresentou os maiores gaps, com magnitudes superioras a -3. Sugere-se aos administradores que construam, a curto prazo, um plano de metas que visem o aperfeiçoamento dos serviços oferecidos pela organização.

No mais, o conjunto de ações apontado pelas matrizes de posicionamento competitivo e de avaliação de desempenho podem subsidiar às decisões gerenciais de aperfeiçoamento dos níveis de serviço prestados pelas escolas públicas. Dentre outras possibilidades, é possível redirecionar recursos e esforços que apoiam atributos nas zonas de excesso para suplantar déficits de qualidade em outros muito importantes para os alunos. É importante concentrar esforços nas variáveis em que os alunos conferem alta importância, onde a instituição tem desempenho abaixo das expectativas e em quais há concorrentes com práticas melhores.

Por fim, recomenda-se que sejam desenvolvidos estudos futuros, no segmento da educação, que avaliem longitudinalmente a qualidade dos serviços. Isso permitirá compreender a dinâmica da formação da qualidade do serviço. 


\section{Referências}

Abdullah, F. (2006). The development of HEdPERF: A new measuring instrument of service quality for the higher education sector. International Journal of Consumer Studies, 6(30), 569-581. doi:10.1111/j.1470-6431.2005.00480.x

Alcântara, V. de C., Luiz, G. V., Ferreira, A. C. e Teodoro, S. A. S. (2012). Dimensões e determinantes da satisfação de alunos em uma instituição de ensino superior. Revista Brasileira de Marketing, 3(11), 193-220. doi:10.5585/remark.v1 1i3.2444

Ali, F.; Zhou, Y., Hussain, K., Nair, P. K. e Ragavan, N. A. (2016). Does higher education service quality effect student satisfaction, image and loyalty? A study of international students in Malaysian public universities. Quality Assurance in Education, 1(24), 70-94. doi:10.1 108/qae-02-2014-0008

Annamdevula, S. e Shekhar, R. (2012). Development of HiEdQUAL for measuring service quality in Indian higher education sector. International Journal of Innovation, Management and Technology, 3, 412-416. doi:10.7763/ijimt.2012.v3.265

Ashraf, M. A., Osman, A. Z. R. e Ratan, S. R. A. (2016). Determinants of quality education in private universities from student perspectives: A case study in Bangladesh. Quality Assurance in Education, 1(24), 123-138. doi:10.1108/qae-09-2013-0040

Alves, T. A. S. (2009). Tecnologias de informação e comunicação (TIC) nas escolas: da idealização à realidade. Estudos de casos múltiplos avaliativos em escolas públicas do ensino médio do interior paraibano brasileira (Dissertação de Mestrado). Universidade Lusófona de Humanidades e Tecnologias, Lisboa, Portugal.

Brochado, A. (2009). Comparing alternative instruments to measure service quality in higher education. Quality Assurance in Education, 17(2), 174-190. doi:10.1108/09684880910951381

Butta, B. Z. e Rehman, K. U. (2010). A study examining the student's satisfaction in higher education. Procedia Social and Behavioral Sciences, 2, 5446-5450. doi: 10.1016/j.sbspro.2010.03.888

Campos, D. F., Martins, L. D. S. e Neto, M. L. (agosto, 2011). Qualidade dos serviços na educação superior: uma visão comparativa entre dois cursos de graduação. Comunicación presentada en el Simpósio de Administração da produção, logística e operações internacionais. São Paulo, Brasil.

Cardona, M. M. e Bravo, J. J. (2012). Service quality perceptions in higher education institutions: the case of a Colombian university. Estudios Gerenciales, 28, 23-29. doi: 10.1016/s01235923(12)70004-9

Cronin, J. J. e Taylor, S. A. (1992). Measuring service quality: a reexamination and extension. Journal of Marketing, 56, 55-68. doi:10.2307/1252296

Cunha, E. A., Andrade, D. M. e Brandão, M. M. (2010). Atributos do serviço educacional na percepção do discente sobre a qualidade. Recuperado de http://www.fucape.br/_public/producao_cientifica/

Deshields J. W., Kara, A. e Kaynak, E. (2005). Determinants of business student satisfaction and retention in higher education: applying Herzberg's two factor theory. International Journal of Educational Management, 2(19), 128-139. doi:10.1108/09513540510582426

Dos Santos, G. S. (2014). Avaliação da qualidade do serviço educacional numa instituição de ensino superior privada: a perspectiva de alunos de graduação em um estudo longitudinal (Dissertação de Mestrado). Universidade Potiguar, Brasil. 
Duarte, L. R. e Piratelli, C. L. (agosto, 2015). Gestão da qualidade de serviços no ensino superior: aplicação do método HEDPERF. Comunicación presentada en el Simpósio de Administração da Produção, Logística e Operações Internacionais. São Paulo, Brasil.

Eberle, L. (2009). Identificação das dimensões da qualidade em serviços: um estudo aplicado em uma instituição de ensino superior localizada em Caxias do Sul, RS. Dissertação de Mestrado. Universidade de Caxias do Sul, Brasil.

Eberle, L., Milan, G. S. e Lazzari, F. (2010). Identificação das dimensões da qualidade em serviços: um estudo aplicado em uma instituição de ensino superior. Revista de Administração de Empresas, 2(9), 1-24. doi:10.1590/s 1676-56482010000200003

Figueroa, M. E. V., Torres, C. M. G., Souza, S. R. e Marchiori, I. C. (2013). Análise quali quantitativa do projeto "primeiro, aprender": avanços e desafios para o processo de ensino e aprendizagem. Caderno de Cultura e Ciência, 12(1), 110-118. doi:10.14295/cad.cult.cienc.v12i1.607

Fitzsimmons, J. A. e Fitzsimmons, M. J. (2005). Administração de serviços: operações, estratégia e tecnologia da informação. Porto Alegre: Bookman.

Grönroos, C. (1984). A service quality model and its marketing implications. European Journal of Marketing, 4(18), 36-44. doi:10.1108/eum0000000004784

IBGE. (2013). Pesquisa anual de serviços. Recuperado de http://www.ibge.gov.br/

INEP. (2016). Censo escolar: resultados finais do censo escolar. Recuperado de http://portal.inep.gov.br/basica-censo

Lankara, V. P. D. e Ye, Y. (2015). A comparative study on students' satisfaction between naung taung monastic high school and kyauk ta lone public high school in southern shan state, Myanmar. Sholar, 1(7), 277-288.

Lourenço, C. D. da S., Knop, M. F. T., Oliveira, V. C. da S. e Silva, M. R. J. D. (abril, 2006). Ensino superior em administração e percepção da qualidade de serviços: uma aplicação da escala SERVQUAL. Comunicación presentada en el Encontro da ANPAD. Salvador, BA, Brasil.

Lovelock, C. e Wright, L. (2006). Serviços, marketing e gestão. São Paulo: Saraiva.

Milan, G. S., Corso, A. e Eberle, L. (agosto, 2013). Atributos e dimensões da qualidade em serviços na percepção de alunos de uma IES. Comunicación presentada en el simpósio de Administração da produção, logística e operações internacionais. São Paulo, Brasil.

Mostafa, M. M. (2007). A comparison of SERVQUAL and I-P analysis: measuring and improving service quality in egyptian private universities. Journal of Marketing for Higher Education, 16, 83 -104. doi:10.1300/j050v16no2_04

Navarro, M. M., Iglesias, P. M. e Torres, R. P. (2005). A new management element for universities: satisfaction with the offered courses. International Journal of Educational Management, 6(19), 505-526. doi:10.1108/09513540510617454

Nyagowaa, H. O., Ocholla, D. N. e Mutula, S. M. (2013). Service quality, user satisfaction and net-benefits' effect on e-School success: the case of NEPAD's e-school pilot in Kenya. Education for Information, 30, 93-115.

Parasuraman, A, Zeithaml, V. A. e Berry, L. L. (1985). A conceptual model of service quality and its implications for future research. Journal of Marketing, 49, 41-50. doi:10.2307/1251430

Ramos, B. S. (2015). Percepção de qualidade das escolas do ponto de vista de alunos do ensino médio. Dissertação de Mestrado. Fundação Getúlio Vargas, Rio de Janeiro, Brasil. 
Ramseook-Munhurrun, P. e Nundlall, P. (2013). Service quality measurement for secondary school setting. Quality Assurance in Education, 4(21), 387-401. doi:10.1108/qae-05-20110025

Radons, D., Battistella, L., Grohmann, M. e Penna, R. (2012). A qualidade dos serviços da coordenação de um curso de graduação e o nível de satisfação dos acadêmicos. REICE. Revista Iberoamericana sobre Calidad, Eficacia y Cambio en Educación, 10(3), 46-57.

Souza, C. C. M., Da Silva, D., Moretti, S. L. A. e Garcia, M. N. (2014). Construção e validação de escala de qualidade de ensino e serviços: um estudo com alunos de cursos de graduação em administração de empresas. REGE, 1(21), 65-82. doi:10.5700/rege5 19

Stock, J. R. e Lambert, D. M. (2001). Strategic logistics management. Nueva York, NY: McGraw Hill.

Tumino, M. C. e Poitevin, E. R. (2013). Evaluación de la calidad de servicio universitario desde la percepción de estudiantes y docentes: caso de estudio. REICE. Revista Iberoamericana sobre Calidad, Eficacia y Cambio en Educación, 12(2), 63-84.

Vergara, J. e Quesada, V. (2011). Análisis de la calidad en el servicio y satisfacción de los estudiantes de ciencias económicas de la Universidad de Cartagena mediante un modelo de ecuaciones estructurales. Revista Electrónica de Investigación Educativa, 13, 108-122. doi:10.4067/s0718-33052011000300011

\section{Breve CV de los autores}

\section{Evadio Pereira Filho}

Graduado en ingeniería de producción por la Universidad Federal del Rio Grande del Norte. Master en gestión por la Universidad Potiguar. Actualmente conforman el cuerpo de maestros del Instituto Federal de Educación, Ciencia y Tecnología de Paraíba - Campus Patos. Despierta el interés en la investigación en las áreas de gestión de la calidad, la capacidad empresarial y de gestión de servicios. ORCID ID: 0000-0003-33401233. Email: evadio.filho@gmail.com

\section{Fernando Antônio Guimarães Tenório}

Graduado en sistemas de información por el Centro de Estudios Superiores de Maceió. Master en gestión por la Universidad Federal de Sergipe. Actualmente conforman el cuerpo de maestros del Instituto Federal de Educación, Ciencia y Tecnología de Paraíba - Campus Patos. Despierta el interés en la investigación en las áreas de logística, gestión de la información y gestión de servicios. ORCID ID: 0000-0002-6676-8042. Email: fernando.tenorio@ifpb.edu.br

\section{Junior Raimundo da Silva}

Estudiante universitario en Tecnología de Seguridad en el Trabajo por el Instituto Federal de Educación, Ciencia y Tecnología de Paraiba - Patos Campus. Actualmente él es un compañero de la investigación científica en proyectos relacionados con la gestión de la calidad, la ergonomía y la salud y seguridad en el trabajo. ORCID ID: 0000-00026278-1397. Email: juniorraimundo95@gmail.com 